\title{
Atividades Acadêmicas na Rotina de Crianças Ribeirinhas Participantes do Programa Bolsa Família
}

\author{
Viviam Rafaela Barbosa Pinheiro Freire ${ }^{1}$ \\ Simone Souza da Costa Silva \\ Fernando Augusto Ramos Pontes \\ Júlia de Almeida Roffé Borges \\ Universidade Federal do Pará \\ Maria Lúcia Seidl de Moura \\ Universidade do Estado do Rio de Janeiro
}

\begin{abstract}
RESUMO - Este artigo objetiva descrever a rotina referente à vida acadêmica de crianças atendidas pelo Programa Bolsa Família em uma comunidade ribeirinha amazônica. Participaram do estudo 30 crianças: 16 meninas e 14 meninos. Foram utilizados os Inventários Sociodemográfico e o de Rotina. Os principais resultados indicaram que a atividade de ir para a escola ocupa $16 \%$ de um dia de semana, o dever de casa atinge 3\% e não há leituras fora do ambiente escolar. No fim de semana, as crianças não realizam dever de casa ou leituras. A participação parental na rotina dos filhos e filhas é restrita. Ações de envolvimento e capacitação das famílias ribeirinhas são necessárias para que estas participem e estruturem atividades acadêmicas nas rotinas das crianças.
\end{abstract}

Palavras-chave: atividades acadêmicas, bolsa família, crianças ribeirinhas, desenvolvimento humano, rotina

\section{Academic Activities in the Routine of Riverine Children who Participate in the Bolsa Família Program}

\begin{abstract}
This article aims to describe the routine related to academic life of children who participate in the Bolsa Família Program in an Amazon riverside community. A Sociodemographic and a Routine Inventory were administered to 30 children: 16 girls and 14 boys. The main results indicate attending school occupies $16 \%$ of their weekday, homework $3 \%$ and no reading activities take place outside the school. In the weekend, children do not make homework or develop reading activities. Parental participation in the routine of their sons and daughters is restricted. Actions to stimulate involvement and qualification of those riverside community families are necessary so they can participate and organize academic activities in the routine of their children.
\end{abstract}

Keywords: academic activities, Bolsa Família Program, riverine children, human development, routine

O desenvolvimento humano dá-se em contextos específicos, caracterizados por sistemas de crenças e práticas compartilhadas, além do ambiente físico e social (Harkness \& Super, 1996). Essas práticas traduzem-se em rotinas diversas no cotidiano de indivíduos e suas famílias, de forma que a análise de rotinas permite identificar características do contexto em que as crianças estão inseridas e suas oportunidades de desenvolvimento (Bronfenbrenner, 1996; Silva et al., 2010).

Rotinas familiares, segundo Fiese et al. (2002), são padrões de interação que estão submersos nos contextos ecológicos e culturais da família. Podem abranger a vida diária e semanal das crianças, sendo também compreendidas como comportamentos observáveis, repetitivos, com o envolvimento de dois ou mais membros, estando sujeitos a previsibilidade ao longo da vida familiar (Boyce, Jensen, James, \& Peacock, 1983).

1 Endereço para correspondência: Universidade Federal do Pará, Núcleo de Teoria e Pesquisa do Comportamento, Laboratório de Ecologia do Desenvolvimento. Rua Augusto Corrêa, 01 - Guamá. Belém, PA. CEP66075-110.E-mail: led_pbf@yahoogrupos.com.br
Ao prover ordem e estruturação para o cotidiano, as rotinas favorecem o sentimento de estabilidade, coesão e satisfação com a vida familiar, além de atenuar o impacto de experiências estressantes (Jensen, James, Boyce \& Hartnett, 1983). Nesse sentido, as rotinas estão relacionadas à organização e fortalecimento do grupo familiar e influenciam todos os seus membros.

Além desses efeitos relativos ao bem-estar subjetivo dos membros da família, há evidências de que as rotinas contribuem para um melhor desempenho acadêmico, redução de ausência na escola e melhor relacionamento com os colegas e membros da família em idade escolar (Guidubaldi, Cleminshaw, Perry, Nastasi, \& Lightel, 1986). Há também indicações de que rompimentos na rotina familiar estão associados a prejuízos no funcionamento acadêmico e socioemocional das crianças (McLoyd, Toyokawa, \& Kaplan, 2008; Taylor \& Lopez, 2005).

De fato, práticas rotineiras podem ser determinantes para o sucesso acadêmico. Dentre elas, a frequência à escola se destaca como uma atividade fundamental para o desenvolvimento de crianças e adolescentes, pois além de promover a construção do conhecimento e o desenvolvimento de habilidades sociais e cognitivas, protege da exposição a situações 
de risco e vulnerabilidade (Marques, 2001). Dessa forma, o acesso, permanência e sucesso no sistema educacional se configuram como um antídoto à marginalização social (Machado \& Machado, 2008).

Apesar desses benefícios, estudos na área (Bueno \& Garcia, 1996; Chechia \& Andrade, 2005; Lippitz \& Levering, 2002) têm apontado que ir para a escola não é suficiente, havendo a necessidade de se ter continuidade das atividades escolares no contexto familiar. Para os mesmos autores, dessa extensão dependem o sucesso ou insucesso escolar e o fortalecimento do conhecimento e seu significado para a criança. Embora escola e família tenham objetivos, conteúdos e métodos de educação diferenciados, precisam utilizar estratégias que se apoiem mutuamente (Leite \& Tassoni, 2002).

Uma tarefa que ilustra a relação de apoio entre a família e a escola é o dever de casa. Para Carvalho (2004), o dever de casa é parte integrante do processo ensino-aprendizagem, afetando o planejamento e implementação das atividades escolares, assim como da vida dos estudantes fora da escola e sua rotina familiar. A prática do dever de casa, com demandas a serem realizadas fora do horário escolar, faz do lar uma extensão da sala de aula. Com isso, mantém os pais e mães informados e envolvidos no aprendizado de suas crianças.

No entanto, o envolvimento dos familiares na atividade de dever de casa dos filhos e filhas está relacionado, especialmente, a três aspectos destacados por Carvalho (2004) que são: tempo livre, conhecimento sobre as matérias escolares e vontade (gosto). Os dois primeiros afetam, em particular, as camadas menos favorecidas, pois estas estão distantes das expectativas de muitas escolas quando requerem contribuições acadêmicas da família, uma vez que, não apresentam um modelo familiar detentor de capital econômico, repertório escolar, geralmente com uma mãe disponível, além de uma estrutura doméstica de apoio às atividades da escola (Carvalho \& Burity, 2006).

Ainda de acordo com as mesmas autoras, as crianças de classe popular têm seu rendimento acadêmico comprometido, por não realizarem atividades extraescolares e se ocuparem (principalmente as meninas) com tarefas domésticas. Em contraste, crianças de classe média alta, cujas famílias incluem em suas rotinas as tarefas da escola, têm mais possibilidade de uma vida acadêmica bem sucedida (Carvalho \& Burity, 2006). Isso corrobora a hipótese de que a estabilidade gerada por padrões rotineiros favorece a realização de atividades que contribuem para o desenvolvimento intelectual.

Outra tarefa dessa natureza é a atividade de leitura. O envolvimento de familiares, quer no incentivo, quer no compartilhamento de atividades rotineiras de leitura, permite que as crianças estabeleçam conexões entre a linguagem oral e as estruturas do texto escrito, dando sentido aos sinais que visualizam. Dessa forma, seus conhecimentos são expandidos, possibilitando que tenham uma melhor visão de mundo e de si mesmas (Dell'Isola, 1991).

Competências em leitura são essenciais para se obter sucesso na escola, das quais dependem diversas situações acadêmicas. Isso ocorre em virtude da leitura envolver um conjunto de habilidades, como: identificar mais facilmente as informações essenciais do texto; gerar questões sobre o conteúdo lido; construir significados; realizar inferências; estabelecer uma rede de relações entre enunciados, organi- zando as informações que compõem as diferentes partes do texto (Boruchovitch, 2001; Dembo, 2000; Vicentelli, 2000).

Diante disso, a escola se constitui um contexto que estabelece demandas ao sistema familiar, cuja resposta repercute nas conquistas alcançadas pelas crianças e adolescentes ao longo do tempo. No entanto, se por um lado a relação de cooperação entre esses dois contextos tem sido um dos aspectos apontados pela literatura como favorecedor do desenvolvimento, por outro lado, as ausências de metas comuns e de estratégias sincronizadas podem dificultar o alcance dos objetivos nesses dois ambientes (Souza, 2009).

Nesse sentido, a relação entre família e escola tem mais possibilidade de ser bem sucedida quando as pessoas inseridas nesses contextos apresentam perspectivas semelhantes sobre a realidade, especialmente sobre a função do conhecimento nas suas vidas. Essa condição, porém, contrasta com a realidade de comunidades ribeirinhas da Amazônia (Mendes, Pontes et al., 2008), onde o modo de vida depende da agricultura, pesca e extração de recursos da floresta, vivendo as crianças e suas famílias em função da natureza. Dessa forma, o sucesso na escola é prejudicado, já que a sobrevivência não depende de uma formação acadêmica ou conhecimento formal, como em contextos urbanos, mas está fortemente ligada ao conhecimento informal da floresta, rios, ciclos e sua dinâmica (Cruz, 2008).

Pesquisas recentes revelaram que a Amazônia Legal representa 59\% do território brasileiro e inclui 775 municípios onde vivem em torno de 24 milhões de pessoas. O Norte, a região mais representativa da Amazônia Legal, possui cerca de $26,5 \%$ de seu contingente populacional vivendo em zona não-urbana e apresenta o segundo pior Índice de Desenvolvimento Humano do Brasil $(0,764)$, valor que supera apenas o índice de 0,720 da região Nordeste (Instituto Brasileiro de Geografia e Estatística, 2010; Programa das Nações Unidas para o Desenvolvimento, 2005).

Esses dados sugerem que, em contraste com a abundância e diversidade de solos, fauna, flora, etnias e culturas encontradas na Amazônia, seus habitantes têm poucas oportunidades sociais de desenvolvimento (Meirelles, 2004). Com efeito, a riqueza natural do contexto em que vivem as comunidades ribeirinhas da Amazônia se opõe às inúmeras dificuldades existentes, como falta de saneamento básico, de energia elétrica, água potável, além de restrições de saúde, educação, dentre outros (Fraxe, Witkoski, \& Miguez, 2009; Scherer, 2004; Silva, 2006).

Em relação às oportunidades educacionais, há distância entre as escolas e as comunidades, condições precárias de estrutura do ambiente escolar, redução dos profissionais de educação e acesso limitado aos ciclos iniciais do ensino fundamental. Ribeiro e Fabré (2003) também verificaram que as crianças ribeirinhas deixam de frequentar a escola pelo fato de terem de ajudar os pais e mães no trabalho. Além disso, Ribeiro-Souza (2007) verificou que na percepção das mulheres ribeirinhas, como mãe e educadora da sua família, o ofício de ensinar é propriedade da escola. Nesse cenário de dificuldades e carências, é possível que a compreensão da família sobre a função da escola, como também do próprio papel de parceira no processo de desenvolvimento dos filhos e filhas, seja comprometida e limitada (Mendes, Ramos et al., 2008). 
Há restrições também de contatos e vínculos estabelecidos nesse contexto, pois dependem da regulação do rio. Esse mediador, segundo Harris (2000), ao mesmo tempo que limita contatos, muitas vezes é a única forma de mantê-los, atuando como um obstáculo ambiental e meio de acesso, uma barreira e ponte, criando e restringindo as possibilidades de interação. Com isso, adultos e crianças dessas localidades têm contatos sociais limitados fora das famílias (Afonso, 2011; Reis, 2007; Teixeira \& Alves, 2008).

Esses desencontros tornam-se mais preocupantes, diante dos objetivos de políticas públicas focadas em famílias em situação de vulnerabilidade, condição que impõe, especialmente para as crianças, ameaças ao bem-estar e limitação de oportunidades de desenvolvimento humano, como privação social e desvantagem educacional (Hutz, Koller, \& Bandeira, 1996). Nesse âmbito, destaca-se o Programa Bolsa Família, cujos objetivos de longo prazo incluem possibilidades de rompimento com o ciclo de pobreza através das gerações, requerendo, assim, a reorganização na rotina de seus beneficiários.

O Programa Bolsa Família foi criado pelo Decreto $\mathrm{n}^{\circ}$ 5.209, que regulamenta a Lei $\mathrm{n}^{\circ} 10.836$, de 9 de janeiro de 2004, se instituindo a partir da unificação de programas sociais pré-existentes, como Bolsa Escola e Bolsa Alimentação. Seus objetivos abrangem: a) combater a fome e promover a segurança alimentar e nutricional; b) combater a pobreza e outras formas de privação das famílias; c) promover o acesso à rede de serviços públicos, em especial, saúde, educação, segurança alimentar e assistência social; e d) criar possibilidades de emancipação sustentada dos grupos familiares e desenvolvimento local dos territórios (Caixa Econômica Federal, 2011).

A execução do Programa Bolsa Família envolve a transferência mensal de renda para famílias em situação de extrema pobreza (com renda per capita de $\mathrm{R} \$ 70,00$ ) e situação de pobreza (com renda per capita de $\mathrm{R} \$ 140,00$ ), das quais é exigido o cumprimento de condicionalidades. Dentre elas, as famílias beneficiárias assumem o compromisso de manter suas crianças regularmente matriculadas na escola, com frequência mensal mínima de $85 \%$.

Segundo a legislação e os documentos oficiais do Programa, as condicionalidades justificam-se pela possibilidade de acesso e inserção da população pobre nos serviços sociais básicos. Para Ferreira (2010), a ideia subjacente ao cumprimento das contrapartidas, especialmente a referente à manutenção das crianças na escola, é de que a elevação do nível de educação das crianças poderia criar oportunidades para as novas gerações se inserirem no mercado de trabalho, interrompendo o ciclo de pobreza.

Vários estudos sobre o impacto das condicionalidades do Programa Bolsa Família referentes à educação (Cacciamali, Tatei, \& Batista, 2010; Duarte \& Silveira Neto, 2008; Ministério do Desenvolvimento Social e Combate à fome, 2010) concluíram que o Programa conseguiu aumentar a frequência escolar de crianças e adolescentes, como também reduzir o abandono escolar dos estudantes beneficiários em relação aos dos estudantes não beneficiários no ensino fundamental e médio. Assim, ao exigir o comprometimento das famílias para que as crianças tenham em suas rotinas o ato de frequentar a escola, o programa oportuniza o estabelecimento de relação entre família e escola, atribuindo a ambos a responsabilidade de investimento nas novas gerações.

Todavia, supõe-se que essa rotina, por sua vez, demande outras responsabilidades para as famílias beneficiárias, como o dever de casa e a leitura, que, apesar de não serem exigidos pelo programa, podem favorecer o sucesso acadêmico e, possivelmente, a emancipação dos beneficiários. Sem isso, configuram-se os resultados negativos apontados por Soares, Ribas e Osório (2007), quanto ao mau rendimento escolar dessas crianças atendidas pelo Programa Bolsa Família.

Considerando que o programa atinge contextos diversos no Brasil, há pouco conhecimento de como as famílias ribeirinhas da Amazônia se ajustam para cumprir as condicionalidades, particularmente, a relacionada com a educação. Além disso, a literatura referente à participação de famílias ribeirinhas da Amazônia no Programa Bolsa Família ainda é precária.

Assim, em função das metas colocadas aos beneficiários e do pouco conhecimento de como o cumprimento das condicionalidades de educação é viabilizado no cotidiano de famílias ribeirinhas atendidas pelo programa, esta pesquisa buscou contribuir para reduzir uma lacuna na área. Para isso, focalizou um aspecto que se considera fundamental para o alcance de metas: o da rotina acadêmica das crianças que vivem às margens de rios na Amazônia, especificamente as atividades de ir para a escola, fazer o dever de casa e realizar leituras. Conhecer essas rotinas permite o entendimento do valor da escola para essas famílias e o desenvolvimento de estratégias psicossociais de intervenção que favoreçam o sucesso do programa.

\section{Método}

\section{Participantes}

Foram participantes desta pesquisa 30 crianças ribeirinhas de uma ilha na Amazônia, sendo 16 do sexo feminino e 14 do masculino. Foram critérios de seleção: ser estudante do $1^{\circ}$ ou do $2^{\circ}$ ciclo de uma das escolas municipais do local; e estar na faixa etária de 6 a 11 anos.

\section{Ambiente}

A pesquisa foi realizada em uma comunidade que vive às margens de alguns rios que compõem a Área de Proteção Ambiental (APA) da ilha do Combú, estado do Pará - Brasil. Com uma extensão territorial aproximada de $15 \mathrm{~km}^{2}$, a ilha do Combú está distante do centro da capital cerca de 1,5 $\mathrm{km}$ por via fluvial, caracterizando-se por ser uma floresta de várzea com diversificada composição florística, além de possuir enormes atrativos turísticos e comerciais (Freire, Júnior, Vitorino, Jardim, \& Sousa, 2010).

A composição vegetal da ilha abrange uma área composta de cipós, árvores, arbustos, lianas e espécies de sub-bosques. Apresenta também em sua estrutura e composição árvores de grande porte, matas primária e secundária e solos razo- 
avelmente férteis, onde há a predominância do açaizeiro (Dergan, 2006).

Considerada a quarta maior ilha do município de Belém, Combú está situada às margens do rio Guamá. Nessa área vivem 375 famílias ou aproximadamente 1.700 moradores que se concentram em quatro comunidades: Igarapé do Combú, Igarapé do Piriquitaquara, Furo da Paciência e margem do Rio Guamá (Prefeitura Municipal de Belém, 2001).

Apesar da proximidade com a capital Belém, a ilha do Combú apresenta dificuldades diversas, tais como a presença de apenas uma unidade de saúde, carências de energia, água potável e saneamento básico. No âmbito educacional, os moradores contam com três unidades pedagógicas que permitam o acesso até o $2^{\circ}$ ciclo do ensino fundamental.

Teixeira e Alves (2008) analisaram o cotidiano das crianças na ilha do Combú e verificaram que suas atividades são comuns às dos adultos, especialmente seus pais e mães. Assim, atividades como travessia à capital para vender os recursos extraídos da floresta, efetuar compras, frequentar aulas ou realizar pequenos serviços, ocorrem geralmente na companhia de crianças, o que as faz participar da vida na comunidade, no trabalho, em casa, no lazer e nos eventos religiosos.

\section{Instrumentos}

Inventário Sociodemográfico (ISD). O ISD tem como objetivo caracterizar as famílias e inclui itens como: identificação pessoal dos membros familiares; composição do sistema familiar; características do domicílio e saneamento básico; e características econômicas.

Inventário de Rotina (IR). O IR é caracterizado pelo levantamento e classificação de três itens: as atividades, locais e companhias de atividades rotineiras. Esse instrumento, devido às necessidades de sistematização desta e de outras pesquisas, passou por uma reestruturação após um período de teste com famílias ribeirinhas (Silva et al., 2010). Atualmente, o IR é composto por uma planilha, na qual se identificam a atividade de rotina, como também a duração, o local e companhia de sua execução.

A cada família foram aplicados dois inventários, um relativo à rotina de um dia de semana e outro em relação ao fim de semana. A aplicação desse instrumento dá-se considerando dois aspectos: os fatos ocorridos no dia imediatamente anterior ao dia da aplicação e as atividades realizadas no último domingo. Não se questionou sobre o sábado por ser um dia de trabalho para muitos pais e mães, tal como nos dias de semana.

\section{Procedimentos de Coleta e Análise de Dados}

Inicialmente, houve um contato com a coordenadora da unidade pedagógica para explicar os objetivos do projeto e firmar parceria na identificação de crianças beneficiárias do Programa Bolsa Família. Posteriormente, por meio da análise dos registros escolares de tais alunos e alunas, foi feita uma pré-seleção daqueles que participariam da pesquisa, segundo os critérios de idade (crianças de 6 até 11 anos) e de ciclo (alunos pertencentes ao $1^{\circ}$ ou $2^{\circ}$ ciclo).
Após aceitarem a participação das crianças nesta pesquisa, os pais e/ou mães assinaram o Termo de Consentimento Livre e Esclarecido que consta no anexo do projeto aprovado pelo CEP-ICS/UFPA sob o registro de $n^{\circ}$ 203/10. Então, iniciou-se o período de inserção ecológica (Cecconello \& Koller, 2003) na escola, por meio da participação em reuniões e eventos, o que facilitou a habituação dos pesquisadores com as crianças e suas famílias.

Em seguida a essa etapa, iniciou-se a coleta de dados na casa das crianças. O Inventário Sociodemográfico foi o primeiro a ser aplicado, servindo como instrumento de inserção ecológica (Mendes, Pontes et al., 2008). Posteriormente, procedeu-se à aplicação do Inventário de Rotina. Ambos foram respondidos pelo responsável (geralmente a mãe), com ou sem a ajuda da criança.

A análise dos dados do Inventário Sociodemográfico serviu de base para a caracterização das crianças e suas famílias, objetivando traçar um perfil dos pesquisados. O inventário de rotina permitiu fazer uma descrição das principais atividades desenvolvidas pelas crianças beneficiárias do Programa Bolsa Família, o tempo e as pessoas com quem compartilham sua rotina, com ênfase para as tarefas de ir para a escola, fazer o dever de casa e leituras.

\section{Resultados e Discussão}

Os resultados desta pesquisa serão apresentados em dois tópicos, relacionados aos instrumentos utilizados. O primeiro corresponde aos dados sociodemográficos e o segundo aos dados de rotina.

\section{As Famílias Estudadas}

No que se refere aos participantes desta pesquisa $(n=30)$, a maioria das crianças ( $90 \%$ ) vive com os pais, mães, irmãos e irmãs, enquanto que a minoria $(10 \%)$ mora com apenas um dos genitores ou com parentes próximos. Do total de crianças, muitas residem em casas de madeira $(96,7 \%)$, compostas de três a quatro cômodos $(53,3 \%)$, nos quais convivem até cinco moradores $(60 \%)$. A fonte de energia que predomina é a de gerador $(90 \%)$, sendo que em apenas $13,3 \%$ dos lares é possível encontrar geladeira, fogão, televisão, rádio e cama.

O saneamento básico em que as famílias vivem se apresenta bastante ineficiente. O lixo é queimado em 93,3\% das casas e não há instalação de esgotos sanitários, ficando a maior parte dos banheiros $(63,3 \%)$ em contato com o solo e com o rio. Nesse contexto, os respondentes relataram que as doenças mais frequentes nos membros familiares são febre, diarreia e gripe.

Quanto ao perfil ocupacional das mães $(n=30)$, verificou-se que $53,4 \%$ era dona de casa, seguindo-se as funções de diaristas $(20 \%)$, extrativistas de açaí $(13,4 \%)$, vendedora autônoma $(3,3 \%)$, auxiliar de barqueiro $(3,3 \%)$, estagiária $(3,3 \%)$ e recepcionista $(3,3 \%)$. A baixa escolaridade predominava entre essas mães, uma vez que $63,4 \%$ estudaram até a $5^{\mathrm{a}}$ série do ensino fundamental, $23,3 \%$ cursaram entre a $6^{\mathrm{a}}$ e $8^{\mathrm{a}}$ série, e $10 \%$ encerraram os estudos no ensino médio. 
Uma delas, porém, frequentava o ensino superior, no curso de Pedagogia.

Os pais $(\mathrm{n}=27)$, por sua vez, possuíam como principais atividades ocupacionais o extrativismo de açaí (63\%), a pesca $(7,4 \%)$ e a carpintaria $(7,4 \%)$. Em menor proporção, havia desempregado $(3,7 \%)$, operador de motosserra $(3,7 \%)$, trabalhador de serviços gerais $(3,7 \%)$, beneficiário do Instituto Nacional do Seguro Social (3,7\%), auxiliar de um posto de saúde $(3,7 \%)$ e outros $(3,7 \%)$. Em relação à escolaridade, observou-se que $63 \%$ destes pais estudaram até a $5^{\mathrm{a}}$ série do ensino fundamental, $14,8 \%$ cursaram entre a $6^{\mathrm{a}}$ e $8^{\mathrm{a}}$ séries do ensino fundamental, 7,4\% cursaram até o $1^{\circ}$ ano do ensino médio, $7,4 \%$ nunca estudaram, e $7,4 \%$ não souberam responder.

A caracterização dessas famílias revela diferenças em relação a outras comunidades que moram às margens dos rios da Amazônia, pois não apresentam o isolamento geográfico de outras populações ribeirinhas que possuem pouco ou nenhum contato com mídias televisivas, radiofônicas e com outras comunidades e culturas (Mendes, Ramos et al., 2008). No entanto, as famílias dessa ilha assemelham-se às de outras comunidades ribeirinhas, especialmente, em termos de estrutura familiar (Silva, 2006), sistema educacional (Mendes, 2008), falta de saneamento básico e condição de vulnerabilidade social (Scherer, 2004).

Quanto aos aspectos econômicos, $71 \%$ das famílias sobrevivem com renda per capita de até $1 / 4$ do salário mínimo; $21 \%$, com renda de até $1 / 2$ salário mínimo e $8 \%$ não responderam. Destaca-se, nesse aspecto, que a renda foi calculada considerando o salário base de $\mathrm{R} \$ 545,00$, como também o período de safra do açaí, época em que há maior produtividade na região.

Dentre as crianças investigadas ( $\mathrm{n}=30$ ): $29 \%$ são beneficiárias do Programa Bolsa Família por um período de até dois anos; $21 \%$ são beneficiárias de dois a quatro anos; $21 \%$ são beneficiários de quatro a seis anos; $16 \%$ recebem o benefício há mais de seis anos; e 13\% dos respondentes não souberam o tempo de participação no programa.

Quando questionados sobre como utilizaram o valor do benefício no mês anterior, foram relatados por ordem de frequência: compra de vestuário $(\mathrm{n}=15)$; material escolar $(\mathrm{n}=11)$; alimentos $(\mathrm{n}=4)$; pagamento de contas $(\mathrm{n}=4)$; remédios $(n=2)$; e outros $(n=1)$. O uso do benefício entre as famílias deste estudo corresponde aos dados encontrados em pesquisas de nível nacional (Instituto Brasileiro de Análises Sociais e Econômicas, 2008), que confirmam uma maior utilização do valor recebido com alimentos, material escolar, vestuário e remédios.

\section{Rotina}

Considerando um dia qualquer de semana, foi verificado que $42 \%$ do dia são dedicados ao descanso, $21 \%$ ao lazer, $19 \%$ são gastos com atividades acadêmicas, $11 \%$ com alimentação e higiene, $3 \%$ com deslocamento, $3 \%$ com tarefas domésticas e $1 \%$ com eventos religiosos. No domingo, o tempo dedicado a quase todas as atividades rotineiras é alterado, ficando $45 \%$ do dia com descanso, $35 \%$ com lazer, $11 \%$ com alimentação e higiene, sendo que os eventos religiosos, o deslocamento e a tarefa doméstica compartilham o mesmo percentual (3\%). A maior distinção de tempo, no entanto, é verificada nas atividades relacionadas à vida acadêmica, cujo percentual demonstra que não compõem a rotina no fim de semana $(0 \%)$. Essa distribuição de atividades confirma os dados de Teixeira e Alves (2008) sobre o cotidiano das crianças na ilha do Combú, que envolve atividades não diversas das dos adultos, especialmente seus pais e mães, na vida da comunidade e em casa.

Foi verificado que na maior parte do tempo, de um dia de semana ou de fim de semana, as crianças $(n=30)$ realizam suas diversas atividades de rotina sozinhas (44\%). Podem também, em dia de semana, compartilhar da companhia dos irmãos e irmãs (18\%), amigos e amigas (16\%), parentes próximos - como tios, tias, primos e primas - $(10 \%)$, mãe $(6 \%)$, pai e mãe juntos $(3 \%)$, a família completa $(2 \%)$ e outros $(1 \%)$. Em dia de fim de semana, é alterado o tempo de companhia dos parentes próximos (19\%), irmãos e irmãs $(17 \%)$, mãe $(7 \%)$, amigos e amigas (5\%), família completa (3\%), pai e mãe juntos (2\%), avós (2\%) e outros (1\%).

Verifica-se que durante a semana as crianças interagem com familiares e amigos, estes provavelmente da escola. Por outro lado, no fim de semana, as interações e compartilhamentos de atividades rotineiras ocorrem essencialmente com familiares. Essa limitação de contatos também foi identificada em outras pesquisas envolvendo crianças ribeirinhas na Amazônia (Afonso, 2011; Reis, 2007; Teixeira \& Alves, 2008), sendo relatadas como suas principais causas as dificuldades de acesso e de transporte para outros locais. Percebe-se que as oportunidades e restrições de companhias e vínculos em ambiente ribeirinho dependem, em grande parte, de um importante elemento: o rio, como aponta Harris (2000).

Por sua vez, crianças de contextos urbanos possuem maiores oportunidades de interação social, particularmente, por meio de brincadeiras que ocorrem no espaço da rua (Silva, Monteiro, Pontes, Magalhães, \& Silva, no prelo). Isso ocorre devido a tal área permitir um brincar que não apenas é compartilhado por um grupo de crianças, mas também inclui todo o entorno de sujeitos que, de algum modo, interage com os praticantes (Silva et al., no prelo).

Frente às principais companhias e atividades desempenhadas pelo grupo pesquisado de crianças ribeirinhas beneficiárias do Programa Bolsa Família, foram analisadas as atividades acadêmicas e sua relevância na rotina diária. Trata-se das tarefas de ir à escola, que compõe uma das exigências do programa, como também o dever de casa e realização de leituras no ambiente extraescolar.

Em relação às atividades acadêmicas na rotina das crianças ribeirinhas foi verificado que, durante a semana, a atividade de ir para a escola ocupa $16 \%$ de um dia, o dever de casa atinge $3 \%$, não havendo dedicação à leitura fora do ambiente escolar (0\%). No fim de semana, período em que a escola paralisa suas atividades, as crianças não realizam dever de casa nem leituras $(0 \%)$.

A pouca dedicação à vida acadêmica em dia de semana, como também a ausência de realização de tarefas de dever de casa e leituras no fim de semana, talvez demonstrem que, na ausência de compromissos com a rotina escolar, as crianças investigadas não possuem outras demandas ou suporte que 
as incentivem a investir em atividades acadêmicas. Essa realidade também integra outros contextos da Amazônia, como destaca Ribeiro-Souza (2007) sobre a percepção de mulheres acerca da responsabilidade exclusiva da escola no ofício de ensinar. Além disso, segundo a autora, essas mães também se mostraram satisfeitas com a condição que é oferecida por programas como o Bolsa Família para que seus filhos e filhas estudem.

Em se tratando do ato de ir à escola, verificou-se que faz parte da rotina dos dias de semana de todas as crianças investigadas (100\%) nesse contexto. Esse resultado contrasta com os de Ribeiro e Fabré (2003) sobre as crianças ribeirinhas deixarem de frequentar a escola para ajudarem os pais e mães no trabalho. $\mathrm{O}$ contraste entre os dados sobre frequência à escola e as demais rotinas acadêmicas talvez possa ser atribuído ao fato das crianças desta pesquisa serem beneficiárias do Programa Bolsa Família, o que exige das famílias o cumprimento das condicionalidades de educação, isto é, manter tais crianças na escola. Vale lembrar dos resultados positivos do programa comentados anteriormente (Cacciamali et al., 2010; Duarte \& Silveira Neto, 2008; Ministério do Desenvolvimento Social e Combate à Fome, 2010).

Quanto ao dever de casa, verificou-se que se trata de uma atividade executada por $28,6 \%$ das crianças desta pesquisa. As meninas são as que mais desempenham essa atividade extraclasse $(60 \%)$, em contraste com os meninos $(40 \%)$. Deve-se considerar que, tradicionalmente, quando não estão na escola, as meninas ribeirinhas ajudam suas mães nas tarefas domésticas (Silva, 2006), ficando um maior tempo nas dependências do lar, ambiente mais favorável para a realização do dever de casa. Os meninos, por sua vez, geralmente estão envolvidos com o trabalho que o pai realiza (Reis, 2007), passando mais tempo no meio das matas, nos rios e áreas comunitárias, o que pode justificar sua menor participação nas tarefas acadêmicas.

Considerando as crianças que realizam o dever de casa, analisou-se a companhia rotineira de execução de tal atividade. Verifica-se que, na maior parte do tempo, as crianças realizam o dever de casa sozinhas $(57 \%)$, mas também podem ter a companhia dos irmãos e irmãs $(28 \%)$, parentes próximos ( $9 \%$ ), ou a presença parcial das mães, isto é, quando executam a tarefa ora sozinhas, ora auxiliadas pelas mães (6\%).

Dentre os aspectos destacados por Carvalho (2004) para o envolvimento reduzido dos pais e mães nos trabalhos escolares destinados para casa, o mais provável para o contexto ribeirinho pesquisado está relacionado à baixa escolaridade da maioria dos responsáveis, conforme evidenciado nos dados sociodemográficos. Dessa forma, as chances de um responsável acompanhar o dever de casa são baixas, possivelmente, em virtude de muitos não possuírem os conhecimentos viabilizados pela escola, além de desconhecerem seu papel para o desenvolvimento dos seus filhos e filhas.

Assim, ao conhecer as rotinas, em particular as relacionadas à vida acadêmica, verifica-se que apesar de as crianças ribeirinhas apresentarem a rotina de ir para a escola, a ausência de outras atividades acadêmicas ao longo do dia dificulta o sucesso acadêmico, que, por sua vez, poderá repercutir no rompimento do ciclo de pobreza. Suas condições remetem ao que Silva (2006) e Mendes (2008) argumentam, isto é, tendem a manter as famílias ribeirinhas nas mesmas estratégias das gerações anteriores, dificultando o salto que as conduziria a um futuro com uma melhor qualidade de vida.

\section{Considerações Finais}

Os dados encontrados nesta pesquisa indicam que o Programa Bolsa Família está presente na rotina das crianças e, consequentemente, de suas famílias, influenciando de maneira positiva na manutenção do ato de frequentar a escola. No entanto, a análise de suas rotinas diárias deixa claro que os impactos do programa no que concerne à educação restringem-se ao cumprimento dessa condicionalidade. Isso pode explicar os resultados animadores de pesquisas que evidenciam os aumentos na frequência (Cacciamali et al., 2010), e ao mesmo tempo desanimadores, quanto aos baixos níveis de aproveitamento escolar (Soares et al., 2007).

É provável que o baixo rendimento dos alunos e alunas esteja relacionado, entre outros aspectos, à pouca realização e ao pouco acompanhamento de atividades acadêmicas nos demais contextos em que a criança vive. Realmente, em um país onde o sistema educacional é restrito à metade do dia, demanda dos outros contextos, principalmente da família, que colaborem com a ação escolar. Portanto, os objetivos do Programa Bolsa Família referentes à educação, como o investimento no capital humano, poderão ser potencializados quando houver mais investimentos em educação qualificada e orientação familiar, especialmente quanto à sua contribuição para o desenvolvimento das crianças.

São evidentes, porém, as dificuldades desses grupos de agirem como parceiros na educação escolar de seus filhos e filhas, seja porque não podem ou porque não sabem como contribuir. Estratégias semelhantes ao Programa Bolsa Família realizadas em outros países também identificaram essa dificuldade, por isso planejaram ações de envolvimento e capacitação das famílias de modo que estas se tornassem agentes de desenvolvimento da próxima geração.

Pode-se citar, como exemplo, o Head Start, um programa de prevenção ao efeito destruidor da pobreza no futuro da sociedade americana que foi iniciado em meados da década de 1960. Seu objetivo era preparar as crianças provenientes de famílias de baixa renda para a escola, combinando serviços de diversas áreas, dentre elas, educação, alimentação, assistência médica e educação de pais, mães e responsáveis (Freitas \& Shelton, 2005). Suas avaliações indicam que os ganhos cognitivos, sociais e educacionais das crianças participantes só puderam ser mantidos pelo envolvimento dos contextos em que as crianças convivem, em particular, a família e a comunidade (Bairrão, 1995).

Considerando a existência de vários modos de viver em um país tão extenso territorialmente como o Brasil, faz-se necessária a busca de estratégias que permitam a superação das limitações, particularmente, nas comunidades ribeirinhas da Amazônia assistidas pelo Programa Bolsa Família. Sugere-se, assim, avançar na investigação de outras comunidades, com novos delineamentos que possibilitem a generalização dos resultados e a elevação do conhecimento acerca dos 
impactos do programa na rotina dos beneficiários que vivem às margens dos rios.

\section{Referências}

Afonso, T. (2011). Famílias de crianças com deficiência mental no contexto ribeirinho amazônico: Percepções de pais moradores da ilha de Combu - PA. Dissertação de Mestrado, Universidade Federal do Pará, Belém.

Bairrão, J. (1995). A Perspectiva ecológica em psicologia da educação. Psicologia, 10, 7-30.

Boruchovitch, E. (2001). Algumas estratégias de compreensão em leitura de alunos do ensino fundamental. Psicologia Escolar e Educacional, 5, 19-25.

Boyce, W. T., Jensen, E. W., James, S. A., \& Peacock, J. L. (1983). The family routines inventory: Theoretical origins. Social Science and Medicine, 17, 193-200.

Bronfenbrenner, U. (1996). A ecologia do desenvolvimento humano: Experimentos naturais e planejados. Porto Alegre: Artes Médicas.

Bueno, B. G., \& Garcia, T. F. (1996). Êxito escolar: As regras da interação na sala de aula. Revista Brasileira de Estudos Pedagógicos, 77, 263-281.

Cacciamali, M. C., Tatei, F., \& Batista N. F. (2010). Impactos do programa bolsa família federal sobre o trabalho infantil e a frequência escolar. Revista de Economia Contemporânea, 14, 269-301.

Caixa Econômica Federal. (2011). Caixa - Bolsa Família. Retrieved from http://www.caixa.gov.br/voce/social/transferencia/ bolsa_familia/index.asp.

Carvalho, M. E. P. (2004). Escola como extensão da família ou família como extensão da escola? O dever de casa e as relações família-escola. Revista Brasileira de Educação, $25,94-104$.

Carvalho, M. E. P., \& Burity, M. H. (2006). Dever de casa. Visões de mães e professoras. Olhar de Professor, 9, 31-46.

Cecconello, A. M., \& Koller, S. H. (2003). Inserção ecológica na comunidade: Uma proposta metodológica para o estudo de famílias em situação de risco. Psicologia: Reflexão e Crítica, 16, 515-524

Chechia, V. A., \& Andrade, A. S. (2005). O desempenho escolar dos filhos na percepção de pais de alunos com sucesso e insucesso escolar. Estudos de Psicologia, 10, 431-440.

Cruz, V. C. (2008). O rio como espaço de referência identitária: reflexões sobre a identidade ribeirinha na Amazônia. In S. C. Trindade Júnior \& M. G. C. Tavares (Eds.), Cidades Ribeirinhas na Amazônia - mudanças e permanências (pp. 611-616). Belém: EDUFPA.

Dell'Isola, R. L. P. (1991). Leitura: Inferências e contexto sociocultural. Belo Horizonte: Universitária.

Dembo, M. H. (2000). Motivation and learning strategies for college success: A self- management approach. Mahwah, NJ: Lawrence Erlbaum Associates.

Dergan, J. M. B. (2006). História, memória e natureza: As comunidades da ilha do Combu-Belém-PA. Dissertação de Mestrado, Universidade Federal do Pará, Belém.
Duarte, G. B., \& Silveira Neto, R. M. (2008, Dezembro). Avaliando o impacto do programa Bolsa Família sobre a frequência escolar: O caso da agricultura familiar no nordeste do Brasil. Trabalho apresentado no Encontro Nacional da Associação Nacional dos Centros de Pós-Graduação em Economia, Salvador.

Ferreira, N. V. T. (2010). Programa Bolsa Família: O velho com novas roupagens. Retrieved from http://web3.ufes.br/ppgps/ sites/web3.ufes.br.ppgps/files/ Nildete\%20Virginia\%20 Turra.pdf.

Fiese, B. H., Tomcho, T. J., Douglas, M., Josephs, K., Poltrock, S., \& Baker, T. (2002). A review of 50 years of research on naturally occurring family routines and rituals: Cause for celebration? Journal of Family Psychology, 16, 381-390.

Fraxe, T. J. P., Witkoski, A. C., \& Miguez, S. F. (2009). O ser da Amazônia: Identidade e invisibilidade. Ciência e Cultura, 61, 30-32.

Freire, A. S. C., Júnior, P. P. F., Vitorino, M. I., Jardim, M. A. G., \& Sousa, A. M. L. (2010, Setembro). Avaliação dos indices de vegetação (NDMI e NDVI) para a ilha do Combu, Belém-PA, aplicando técnicas de sensoriamento remoto. Trabalho apresentado no XVI Congresso Brasileiro de Meteorologia, Belém.

Freitas, L. B. L., \& Shelton, T. L. (2005). Atenção à primeira infância nos EUA e no Brasil. Psicologia: Teoria e Pesquisa, 21, 197-205.

Guidubaldi, J., Cleminshaw, H. K., Perry, J. D., Nastasi, B. K., \& Lightel, J. (1986). The role of selected family environment factors in children's post-divorce adjustment. Family Relations, 35, 141-151.

Harkness, S., \& Super, C. M. (1996). Introduction. In S. Harkness \& C. M. Super (Eds.), Parents' cultural belief systems: Their origins, expressions and consequences ( $2^{\text {nd }}$ ed., pp. 1-23). New York: The Guilford Press.

Harris, A. G. (2000). Life on the Amazon: The anthropology a Brazilian peasant village. New York: Oxford University Press/ The British Academic.

Hutz, C. S., Koller, S. H., \& Bandeira, D. R. (1996). Resiliência e vulnerabilidade em crianças em situação de risco. Coletâneas da ANPEPP, 1, 79-86.

Instituto Brasileiro de Análises Sociais e Econômicas. (2008). Repercussões do Programa Bolsa Família na segurança alimentar e nutricional das famílias beneficiadas. Retrieved from http://www.ibase.br/userimages/ibase bf sintese site.pdf.

Instituto Brasileiro de Geografia e Estatística. (2010). Censo Nacional - Instituto Brasileiro de Geografia e Estatística. Retrieved from http://censo2010.ibge.gov.br/resultados

Jensen, E. W., James, S. A., Boyce, W. T., \& Hartnett, S. A. (1983). The family Routines Inventory: Development and validation. Social Science and Medicine, 17, 201-211.

Leite, S. A. S., \& Tassoni, E. C. M. (2002). A afetividade em sala de aula: As condições de ensino e a mediação do professor. In R. Azzi, \& A. Sadalla (Eds.), Psicologia e formação docente (pp. 113-141). São Paulo: Casa do Psicólogo.

Lippitz, W., \& Levering, B. (2002). And now you are getting a teacher with such a long name. Science, 18, 205-213.

Machado, A. V., \& Machado, M. C. V. (2008). Escola que protege: Histórico jurídico de proteção da criança e do adolescente. In P. V. B. Silva, J. E. Lopes, \& A. Carvalho (Eds.), Por uma escola que protege: A educação e o enfrentamento à violência contra crianças e adolescentes (pp. 75-93). Ponta Grossa: UEPG. 
Marques, R. (2001). Professores, família e projecto educativo. Porto: Asa Editores.

McLoyd, V. C., Toyokawa, T., \& Kaplan, R. (2008). Work demands, work family conflict, and child adjustment in African-American families: The mediating role of family routines. Journal of Family Issues, 29, 1247-1267.

Meirelles, J. Filho. (2004). O livro de ouro da Amazônia: Mitos e verdades sobre a região mais cobiçada do Planeta. Rio de Janeiro: Ediouro.

Mendes, L. S. A. (2008). A escola enquanto contexto de desenvolvimento: um estudo ecológico em uma comunidade ribeirinha na ilha do Marajó. Tese de Doutorado, Universidade Federal do Pará, Belém.

Mendes, L. S. A., Pontes, F. A. R., Silva, S. S. C., BucherMaluschke, J. S. N. F., Reis, D. C., \& Baía-Silva, S. D. (2008). Inserção ecológica no contexto de uma comunidade ribeirinha amazônica. Revista Interamericana de Psicologia, 42, 1-10.

Mendes, L. S. A., Ramos, T. S., Pontes, F. A. R., Reis, D. C., Silva, S. S. C. \& Silva, S. D. B. (2008). A prática docente em uma escola ribeirinha na ilha do Marajó: Um estudo preliminar em contexto naturalístico, Educação, 31, 80-87.

Ministério do Desenvolvimento Social e Combate à Fome. (2010). Programa Bolsa Família. Retrieved from http://www4. planalto.gov.br/consea/documentos/ transferencia-de-renda/ programa-bolsa-familia-apresentacao-mds

Programa das Nações Unidas para o Desenvolvimento. (2005). Ranking do IDH dos estados. Retrieved from http://www. pnud.org.br/pobreza_desigualdade/ reportagens/index. php?id01=3039\&lay=pde

Prefeitura Municipal de Belém. (2001). Projeto Família Saudável. Belém: Autor.

Reis, D. C. (2007). Cultura da brincadeira em uma comunidade ribeirinha na ilha do Marajó. Dissertação de Mestrado, Universidade Federal do Pará, Belém.

Ribeiro, M. O. A., \& Fabré, N. N. (2003). S.A.S - Sistemas Abertos Sustentáveis: Uma alternativa de gestão ambiental na Amazônia. Manaus: Edua.

Ribeiro-Souza, M. J. R. (2007). Mulher ribeirinha: Educação e familia. Retrieved from http://www.itaporanga.net/genero/1/ GT14/06.pdf

Scherer, E. F. (2004, Setembro). Mosaico terra-água: A vulnerabilidade social ribeirinha na Amazônia. Trabalho apresentado no VIII Congresso Luso-Afro-Brasileiro de Ciências Sociais, Coimbra, Portugal.
Silva, S. S. C. (2006). Estrutura e dinâmica das relações familiares de uma comunidade ribeirinha da região amazônica. Tese de Doutorado, Universidade de Brasília, Brasília.

Silva, S. D. B., Monteiro, E. F., Pontes, F. A. R., Magalhães, C. M. C., \& Silva, S. S. C. (no prelo). Brincadeiras de rua em Belém-PA: Uma análise de gênero e idade. Psicologia: Teoria e Prática.

Silva, S. S. C., Pontes, F. A. R., Santos, T. M., Bucher-Maluschke, J., Mendes, L.S.A., Reis, D. C. \& Silva, S. D. B. (2010). Rotinas familiares de ribeirinhos amazônicos: Uma possibilidade de investigação. Psicologia: Teoria e Pesquisa, 26, 341-350.

Soares, F. V., Ribas, R. P., \& Osório, R. G. (2007). Avaliando o impacto do Programa Bolsa Família: Uma comparação com programas de transferência condicionada de renda de outros países. Brasília: MDS. Retrieved from http://www.ipc-undp. org/pub/port/IPCEvaluationNote1.pdf

Souza, P. B. M. (2009). Configuração do mesossistema entre professores e pais de alunos com deficiência. Dissertação de Mestrado, Universidade Federal do Pará, Belém.

Taylor, R. D., \& Lopez, E. (2005). Family management practice, school achievement, and problem behavior in African American adolescents: Mediating processes. Applied Developmental Psychology, 26, 39-49.

Teixeira, S. R. S., \& Alves, J. M. O. (2008). Contexto das brincadeiras das crianças ribeirinhas da ilha do Combu. Psicologia: Reflexão e Crítica, 21, 374-382.

Vicentelli, H. (2000). Problemática de la lectura en estudiantes universitários. Psicologia Escolar e Educacional, 3, 195-202.
Recebido em 14.02.2012

Primeira decisão editorial em 04.04.2012

Versão final em 26.11.2012

Aceito em 10.12.2012 